\title{
TERCEIRIZAÇÃO NOS TEMPOS DO CÓlERA: O AMOR DO SETOR PÚBLICO À PRECARIEDADE
}

\author{
SELMA VENCO ${ }^{1}$
}

\begin{abstract}
RESUMO: O presente artigo tem como objetivo analisar a política educacional paulista em especial no que tange às relações de trabalho praticadas pela Secretaria Estadual de Educação de São Paulo. A pesquisa, de caráter qualitativo, analisou as formas de contratação de professores no período compreendido entre 1999 e 2015. Essas, articuladas a outras medidas, levou à constatação da adoção do Estado gerencial, implementado em 1995 pelo então presidente Fernando Henrique Cardoso, que conferiu amparo político e legal para que, em São Paulo, governado pelo mesmo partido político, servisse de um fidedigno laboratório social para experienciar o gerencialismo. A nova gestão pública, seguindo seus preceitos oriundos do setor privado, indica: a redução de custos, o aumento da eficiência nas esferas operacionais e gerenciais, refinamento das formas de controle sobre os professores e a tentativa de prescrever o trabalho intelectual baseando-se na estandardização dos conteúdos e aulas a serem avaliadas em série posteriormente.

Palavras-chave: Trabalho docente. Política educacional. Gestão pública.
\end{abstract}

\section{OUTSOURCING IN THE TIME OF CHOLERA: THE LOVE OF THE PUBLIC SECTOR TO THE PRECARIOUSNESS}

ABSTRACT: This article aims to analyze the educational policy especially the labor relations practiced by the State Department of Education of São Paulo-Brazil. The qualitative research analyzed the forms of teacher's hiring in the period between 1999 and 2015. Those ones were articulated with other measures leads to the adoption of the managerialism, implemented in 1995 by President Fernando Henrique Cardoso, who gave political and legal support for in São Paulo, governed by the same political party, serve as a reliable social laboratory to experience managerialism. The new public management, following its precepts from the private sector, states bring cost reduction, increased efficiency in operational and managerial levels, refinement of the forms of control over teachers, and the attempt to prescribe intellectual work is based the standardization of content and lessons to be evaluated in later series.

Keywords: Teaching work. Educational politics. Public management.

\section{EXTERNALIZACIÓN EN LOS TIEMPOS DEL CÓLERA: EL AMOR DEL SECTOR PÚBLICO A LA PRECARIEDAD}

RESUMEN: Este artículo tiene como objetivo analizar la política educativa de São PauloBrasil especialmente con respecto a las relaciones laborales practicadas por el Departamento de Educación del Estado de Sao Paulo. La investigación cualitativa analiza las formas de contratación de profesores en el período entre 1999 y 2015. Ellas articuladas con otras medidas conducen al descubrimiento de la adopción del gerencialismo,

\footnotetext{
${ }^{1}$ Doutora em Educação. Docente da Universidade Estadual de Campinas - UNICAMP. selma.venco@gmail.com.
} 
implementado en 1995 por el presidente Fernando Henrique Cardoso, que dio el apoyo político y jurídico a São Paulo, que se regía por el mismo partido político y sirvió como un laboratorio social fiable para experimentar el gerencialismo. La nueva gestión pública, siguiendo los preceptos del sector privado, establece: reducción de costes, mayor eficiencia en los niveles operativos y de gestión, el refinamiento de las formas de control sobre los profesores, y el intento de prescribir el trabajo intelectual basado la estandarización de los contenidos y lecciones para evaluarse en serie después.

Palabras clave: Trabajo docente. Política educativa. Gestión pública.

\section{Introdução}

O presente artigo tem como objetivo analisar o trabalho docente à luz de determinadas faces da política educacional no Estado de São Paulo, Brasil, e, em especial, a relação estabelecida entre os processos de estandardização de conteúdos, formas de controle sobre o trabalho docente e as relações de trabalho praticadas desde 1995. A análise aqui apresentada é resultado de duas pesquisas de caráter documental e qualitativo ${ }^{2}$ realizadas junto a docentes das escolas públicas estaduais de São Paulo.

Para a realização das entrevistas buscou-se a diversificação entre os participantes concernente a algumas características: sexo, idade, tempo de atuação como professor, tipo de contrato de trabalho e exercendo a profissão em municípios de diferentes portes do interior paulista. Assim, foram ouvidos profissionais com vínculo de trabalho temporário e efetivo, homens e mulheres, com idades entre 19 e 54 anos e com experiência docente entre 3 meses e 24 anos.

O cenário no qual a análise se desenvolve remete a meados dos anos 1990, momento em que se inaugura no Brasil, de forma mais concreta e acelerada, a reestruturação produtiva. Esse fenômeno é assinalado pela acumulação flexível, que, segundo Harvey (1996), abandona a rigidez do fordismo - marcada pela permanência na mesma fábrica durante toda a vida profissional, pelo emprego formal mesmo primando por baixas remunerações e fixação no posto de trabalho - e adota formas flexíveis de contratação e na organização do trabalho. A microeletrônica se expande possibilitando às empresas automatizar as tarefas, demitir em massa e adotar amplamente a terceirização, de forma a conservar em seu bojo as atividades essenciais ao negócio e externalizar as demais. A terceirização das atividades-meio no setor privado contemplou limpeza, segurança, alimentação, produção de pequenas peças nas indústrias, compensação de cheques nos bancos, costura de peças nas confecções etc. Destaque-se, para a análise adiante, a opção das empresas, pois as atividades-fim compreendidas

\footnotetext{
2 Pesquisas financiadas pelo CNPq processo no 401229/2011-4 e no 408885/2013-0.
} 
como a "essência do negócio" não foram terceirizadas. O motor continuou sendo pesquisado no interior das indústrias automobilísticas, a aplicação de capital, nos bancos etc.

Nesse mesmo período, em 1995, o Brasil elegeu o presidente Fernando Henrique Cardoso e inspirado pela vaga de redução de custos na produção, demissão em massa e terceirização, recuperou imediatamente a concepção de Estado Gerencial presente no Decreto-Lei 200 de 1967, em plena ditadura civil militar, baseada, entre outros aspectos, na transferência da Administração Federal à iniciativa privada. Tal ideário fora implantado pelo então ministro da Administração e Reforma do Estado Luiz Carlos Bresser Pereira, orientado pela teoria elaborada pela Nova Direita no Reino Unido e concretizada no governo Margareth Thatcher em 1979, um movimento que fez renascer o neoliberalismo e se posicionou contrariamente aos princípios postulados no Estado do Bem-Estar Social instituído no pós-guerra, a fim de recuperar os países destruídos pela $2^{\mathrm{a}}$ Guerra Mundial. Esse segmento propagou a ideia da ineficiência do Estado, às promessas de futuro embaladas pelos avanços tecnológicos e do peso insuportável carregado pelo conjunto de direitos à população (HALL; GUNTER, 2015). Emergiu, assim, a nova gestão pública.

No Brasil, a premissa para tal opção política reafirmava, por um lado, o papel do Estado como o responsável por formular e financiar as políticas públicas; mas, por outro, reconhecia seu caráter de captador de recursos junto às empresas e ao terceiro setor, com as quais a execução dos serviços públicos, destacadamente saúde e educação, seria compartilhada. Nessa concepção, era premente a ruptura com o Estado Burocrático marcado por forte rigidez e incapaz de responder às transformações provenientes da mundialização e na base técnica do trabalho.

A reforma do Estado possibilitou uma atuação mais direta de organismos como o Banco Mundial, respondendo a um movimento em defesa da administração gerencial, mais afeito ao avanço tecnológico mundial e definida a partir de alguns critérios: orientar a ação do Estado ao "cidadão-cliente"; adotar formas de controle em busca de resultados; e, transferir ações concernentes aos serviços sociais e "científicos competitivos" (BRESSER PEREIRA, 2007).

Assim, compreendeu-se que o Estado deveria primar pela agilidade baseada na flexibilização das organizações e eficiência, busca e controle de resultados. Entretanto, de acordo com seus idealizadores, propiciariam maior fortalecimento do Estado. Na esteira do governo federal seguiu o estadual paulista, aqui compreendido como o laboratório para testar os mecanismos da nova gestão pública, neste artigo focalizada na educação.

Nessa lógica, dois marcos são aqui destacados na transposição do ideário à educação pública: a incorporação da flexibilidade nas relações de trabalho; e, o 'prestar contas', o accountability, por 
parte dos docentes seja ao órgão contratante ou, segundo eles, à própria sociedade. Destaque-se que a crítica aqui tecida não recai sobre qualquer forma do "prestar contas", posto que se trata de recurso público, mas sim concernente ao talhe a ele conferido, dado que a responsabilização é individualizada e, portanto, descompromete, por exemplo, a dimensão da própria política em seus atos. Conforme Afonso (2012, p. 472)

\footnotetext{
Em grande parte dos discursos marcados por este viés político-ideológico, o significado do vocábulo accountability indica frequentemente uma forma hierárquico-burocrática ou tecnocrática e gerencialista de prestação de contas que, pelo menos implicitamente, contém e dá ênfase a consequências ou imputações negativas e estigmatizantes, as quais, não raras vezes, consubstanciam formas autoritárias de responsabilização das instituições, organizações e indivíduos.
}

O Estado gerencial constrói uma política educacional orientada por resultados, equivalente ao lucro nas empresas. Congruente ao posicionamento ideológico passa a adotar medidas oriundas do setor privado tais como o estabelecimento de metas, forte controle sobre docentes e sistemas de avaliação em grande escala, que passamos a analisar.

\section{A “Reestruturação Produtiva” na Educação Pública Paulista}

A reorganização da educação estadual paulista não é, em si, um fato novo, pois, conforme já mencionado, mas, sim, está em curso desde 1995. Para esta análise é significativo remarcar que as políticas sociais configuram-se como elemento crucial para concretização de ajustes de ordem estrutural. Coraggio (1996) pondera ser possível compreender o papel das políticas sociais travestido de "cavalo de Tróia" do mercado, com vistas a pressionar presidente, governadores, prefeitos a adotarem o Estado Mínimo e oferecer educação, saúde e outros direitos à iniciativa privada.

Consideram-se aqui os entraves enfrentados pelo governo do Estado de São Paulo em promover a privatização da educação básica diretamente. Contudo, os movimentos de encorajamento à privatização exógena, segundo Ball e Youdel (2008), se concretizam por meio da legitimação da exploração de serviços voltados à educação pública, com vistas à redução de custos para o Estado e lucros para a iniciativa privada e aplicando a lógica de caráter gerencialista.

A contratação dos docentes seguiu a mesma lógica. Tal opção política possibilitou a aplicação da terceirização dos docentes amparada pelo Decreto $n^{\circ} 2271$ de 7 de julho de 1997, que regula a contratação indireta de profissionais no setor público (BRASIL, 1997). O princípio político e o amparo 
legal foram algumas das condições que abriram caminhos para convalidar a contratação de trabalhadores sem concurso público, bem como para o estabelecimento de parcerias público-privadas, cristalizadas por lei ( $n^{\circ}$ 9.790, de 23 de março de 1999) que regula as Organizações da Sociedade Civil de Interesse Público, as quais, em algumas situações, passaram a assumir parte das responsabilidades do Estado na saúde e na educação.

No que concerne às reformas educacionais no Brasil e, particularmente, no Estado de São Paulo, tais aspectos foram amplamente analisados por pesquisadores da área (MATTOS, 2012; OLIVEIRA, 2001; RIGOLON, 2013; SOUZA, 2002; VENCO; RIGOLON, 2013, 2014) cujas ponderações convergem na constatação da forte presença da racionalidade econômica norteando o setor público educacional. E, reforce-se: ele passa a ser guiado por princípios calcados na eficiência e eficácia. No Estado de São Paulo esses foram expressos pelo estabelecimento de metas a serem cumpridas por cada escola, pela criação de um sistema de avaliação em grande escala, visando mensurar o conhecimento de forma homogênea em contextos heterogêneos e, ainda, associando resultados da avaliação ao fluxo escolar, pautado pela frequência e desistência dos estudantes, de forma a gerar um índice capaz de ranquear as escolas e criar um possível clima tanto de competição quanto de desalento entre escolas conhecedoras de sua condição. A padronização curricular também se materializou na faraônica construção dos cadernos do professor e estudantes, via fundação alinhada politicamente ao mesmo partido político, uma tentativa explícita de prescrever o trabalho intelectual das professoras e professores.

Compreende-se, portanto, que os caminhos da privatização exógena, via terceirização de professores, encontrou terreno fértil no Estado de São Paulo, observando-se na atualidade a dependência, para o funcionamento da escola pública estadual, dos professores contratados temporariamente, garantindo-se, assim, que os estudantes tenham todas, ou a maior parte, das aulas previstas, conforme passamos a analisar. Tal lógica é também compreendida por um dos docentes entrevistados.

[...] é claro que o governo economiza muito dinheiro, porque você imagina quantos categoria "O"3 tem? [...] agora você imagina todo esse montante ele não pagando férias, uma boa economia, né? O que é mais viável pro Estado, ter efetivos ou contratados? Claro que é ter contratado, porque o efetivo é responsabilidade do Estado, o contratado não é... (Professor temporário, 44 anos).

A articulação entre a opção política pela nova gestão pública e, consequentemente, para

\footnotetext{
${ }^{3}$ Categoria O é uma forma de contratação temporária mediante seleção simplificada. Segundo os entrevistados nenhum deles passou por esse processo e, ainda, observou-se nos depoimentos a existência de um desespero pelos diretores ou secretários que buscam substitutos.
} 
práticas de terceirização no setor público educacional paulista é refletida na (não) abertura de concursos públicos para provisão dos cargos docentes. No período compreendido entre 1994 e 2016, ou seja, em 22 anos a Secretaria Estadual de Educação (SEE) -SP realizou 8 concursos para professores licenciados que atuariam no ensino fundamental (séries finais) e ensino médio, em intervalos médios de 5 anos, sendo que em apenas seis deles se menciona a quantidade de vagas.

Rigolon (2013) demonstrou em sua pesquisa que a Secretaria Estadual de Educação do Estado de São Paulo permaneceu durante 15 anos sem realizar concurso para docentes dos anos iniciais. Ou seja: entre 1990 e 2005 esse órgão público, compreende-se aqui, não somente desprezou os efeitos à educação decorrentes de um longo processo sem contratação, como fez uso para viabilizar seu projeto político calcado na redução de custos. Pondera-se, contudo, que a não abertura de concurso público para o referido segmento pode ser explicada apenas em parte pelo processo de municipalização do atual ciclo I do Ensino Fundamental, o qual teve início em 1995, tomando como exemplo apenas o município de São Paulo que não aderiu ao processo de municipalização.

Tais dados referentes aos concursos seriam suficientes para aventar hipóteses sobre o preenchimento dos postos vagos na educação, apenas considerando abandono e aposentadorias. Todavia, são aqui acrescidos os dados estatísticos disponibilizados pela própria Secretaria, sendo possível descortinar o processo de flexibilização em curso posto que, durante todo o segundo semestre de 1999, mais de sete em cada dez professores eram não efetivos, conforme pode ser observado na Tabela 1.

Tabela 1 - Distribuição de professores, segundo formas de contratação, 1999* ( $N^{o}$ abs.)

\begin{tabular}{lcccccccc}
\hline & Jan & Mar & Jul & Ag & Set & Out & Nov & Dez \\
\hline $\begin{array}{l}\text { Efetivos } \\
64.414\end{array}$ & 60.125 & 56.909 & 57.245 & 56.697 & 56.017 & 55.550 & 54.861 \\
$\begin{array}{l}\text { Não } \\
\text { efetivos }\end{array}$ & 132.705 & 115.700 & 135.422 & 135.909 & 139.550 & 147.633 & 149.226 & 145.670 \\
Total & 197.119 & 175.825 & 192.331 & 193.154 & 196.247 & 203.650 & 204.776 & 200.531 \\
\hline
\end{tabular}

* Contemplados professores dos anos iniciais, finais e Ensino Médio (PEBs I e II).

Fonte: SEESP, Coordenadoria de gestão de recursos humanos.

A construção da série histórica, englobando de 2000 a 2015, revela uma oscilação decrescente entre os professores não efetivos, na Tabela 2, a qual destacou para análise os meses de janeiro, de férias escolares, e novembro - mês que registra, entre todos os demais, no período em análise, o maior índice de contratos temporários. Observa-se que até o ano de 2004 o percentual de não efetivos no mês de janeiro é sempre superior ao de efetivos e a partir de 2005 esta relação se inverte, reflexo 
da realização de concurso público. Já nos anos 2005, 2007 e 2011 há pequena superioridade no número de efetivos nos meses de janeiro.

As estatísticas reafirmam a análise de Rigolon (2013) que observou o uso de jargões entre os docentes os quais, mesmo desconhecendo os dados oficiais, se referem à "doença" que acomete os docentes no final do período letivo": outubrite, novembrite, e dezembrite, época em que se registra o maior número de afastamentos de professores. Isso ocorre em razão de não mais conseguirem suportar as péssimas condições de trabalho; período que, com exceção do ano de 2000, em todos os demais anos é caracterizado pelo aumento da contratação de professores com vínculos precários de trabalho (VENCO; RIGOLON, 2014).

Compreende-se por precariedade, com base em Castel (1998), a relação de trabalho caracterizada pela efemeridade, pelo contrato por tempo determinado, pela ausência de direitos vinculados ao trabalho. Nesse sentido, e apoiando-se nos dados da Secretaria é possível afirmar que a precariedade foi amplamente instalada terceirizando o trabalho docente.

Observa-se que, no ano de 2000, os professores não efetivos, no mês de janeiro, representavam praticamente três vezes mais do que os efetivos, ou seja $73 \%$ dos professores eram não concursados; enquanto que em 2015 ocorre a inversão do movimento, posto que os efetivos significavam uma vez e meia os precários, 61\%. A Tabela 2 traz esses dados.

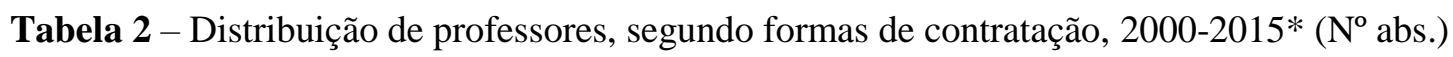

\begin{tabular}{lcccc}
\hline & \multicolumn{2}{c}{ Janeiro } & \multicolumn{2}{c}{ Novembro } \\
\hline $\mathbf{2 0 0 0}$ & Efetivos & Não efetivos & Efetivos & Não efetivos \\
$\mathbf{2 0 0 1}$ & 49.388 & 132.802 & 81.022 & 109.453 \\
$\mathbf{2 0 0 2}$ & 84.874 & 92.446 & 75.874 & 107.504 \\
$\mathbf{2 0 0 3}$ & 83.432 & 94.547 & 79.846 & 121.335 \\
$\mathbf{2 0 0 4}$ & 79.297 & 101.798 & 83.787 & 128.292 \\
$\mathbf{2 0 0 5}$ & 93.370 & 105.194 & 88.731 & 123.971 \\
$\mathbf{2 0 0 6}$ & 106.470 & 94.157 & 100.222 & 116.298 \\
$\mathbf{2 0 0 7}$ & 119.081 & 90.541 & 119.436 & 106.272 \\
$\mathbf{2 0 0 8}$ & 118.258 & 83.016 & 118.434 & 106.785 \\
$\mathbf{2 0 0 9}$ & 125.397 & 84.534 & 125.352 & 95.334 \\
$\mathbf{2 0 1 0}$ & 120.931 & 78.446 & 120.984 & 97.342 \\
$\mathbf{2 0 1 1}$ & 115.814 & 94.809 & 115.987 & 103.844 \\
$\mathbf{2 0 1 2}$ & 123.808 & 101.769 & 116.927 & 106.301 \\
& & 81.573 & 117.623 & 115.174
\end{tabular}




$\begin{array}{lllll}\mathbf{2 0 1 3} & 117.077 & 97.706 & 116.122 & 124.718 \\ \mathbf{2 0 1 4} & 115.668 & 73.926 & 138.708 & 112.028 \\ \mathbf{2 0 1 5} & 137.834 & 88.266 & 129.185 & 93.941\end{array}$

* Contemplados professores dos anos iniciais, finais e Ensino Médio (PEBs I e II).

Fonte: SEESP, Coordenadoria de gestão de recursos humanos.

Observa-se que, mesmo em 2005, momento em que o quadro de docentes é ampliado, ainda assim, em novembro, os professores temporários representavam pouco mais da metade do total de docentes (54\%). Em 2015 o governo paulista adotou medidas, a exemplo da limitação temporal para celebração de contratos precários no intervalo de 200 dias, a chamada "duzentena" ${ }^{4}$, a superlotação de salas e a possibilidade de o docente concursado oferecer outras disciplinas, de acordo com sua formação. $O$ percentual referente aos terceirizados foi de $42 \%$ em novembro. Analisando-se o segmento dos professores licenciados, os números também são significativos, de acordo com o Gráfico 1.

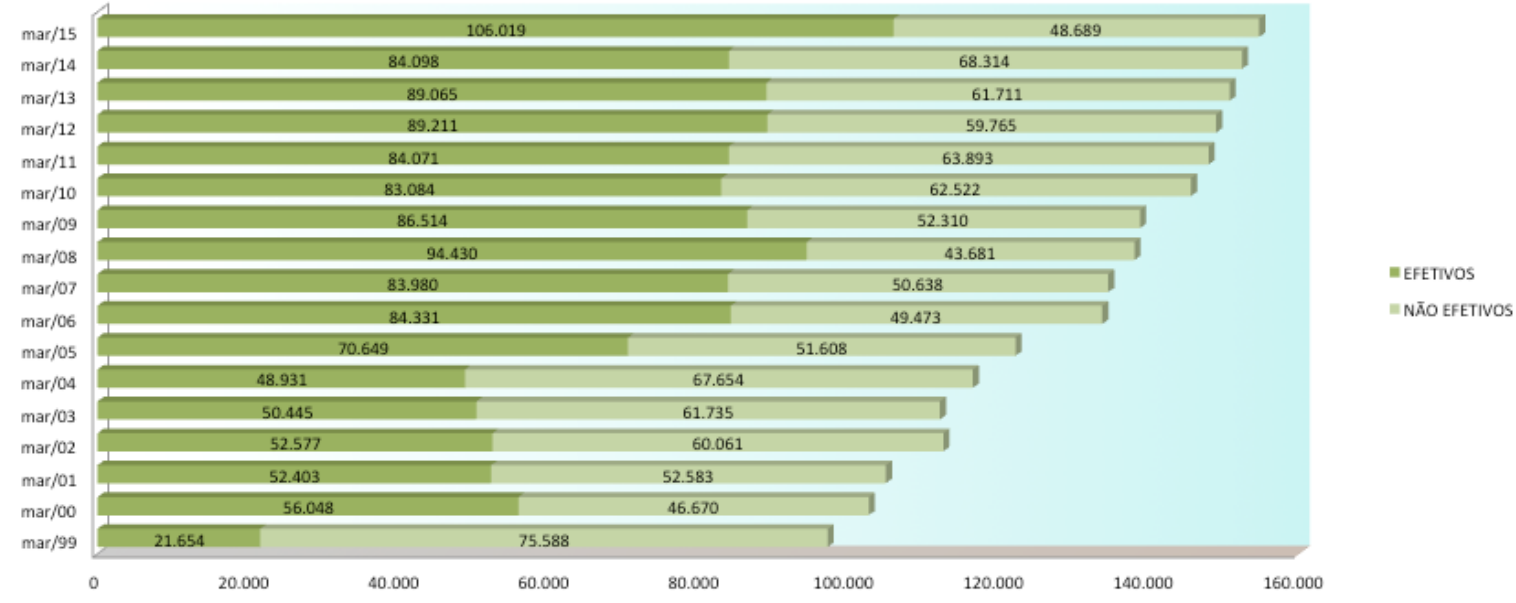

Gráfico 1 - Distribuição de docentes PEB II (Ensinos Fundamental II e Médio), segundo forma de contratação - 1999 a 2015 (n abs). Fonte: SEE-SP.

Ressalte-se o caráter das medidas adotadas via política educacional: mesmo sem razões vinculadas à competitividade e aos ganhos de produtividade assume também a precariedade objetiva (LINHART, 2009), ou seja, é a compra da força de trabalho desrespeitando as leis trabalhistas. A série histórica analisada por região do Estado de São Paulo aponta que a Grande São Paulo (GSP) exibia o maior percentual de professores contratados temporariamente em 2007: 47,8\%. Enquanto na Capital era inferior em seis pontos percentuais em relação à GSP; e, o interior apresentava a menor participa-

\footnotetext{
${ }^{4}$ Norma que impõe um intervalo de 200 dias entre uma contratação e outra do mesmo professor.
} 
ção de precariedade, contudo não desprezível, pois praticamente quatro em cada dez docentes mantinham contrato precário com o Estado (38,66\%). O Gráfico 2 mostra esses dados.

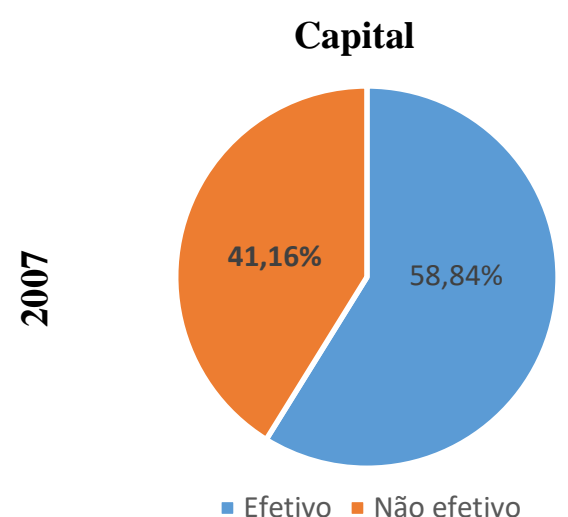

- Efetivo - Não efetivo

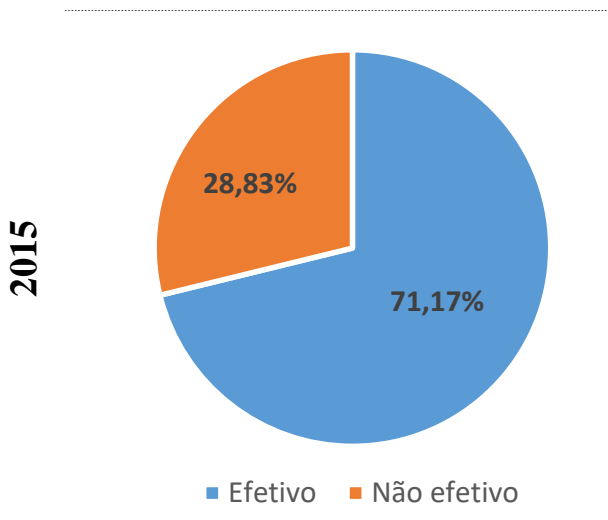

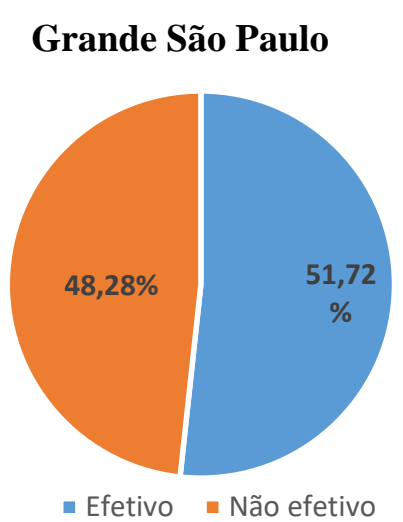

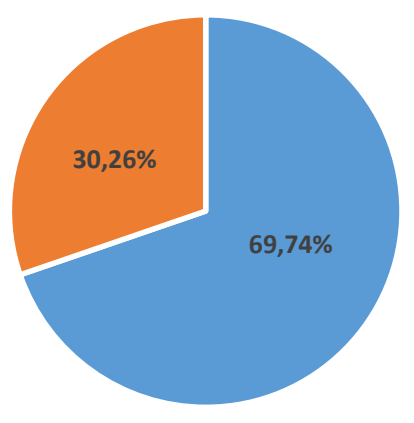

- Efetivo - Não efetivo
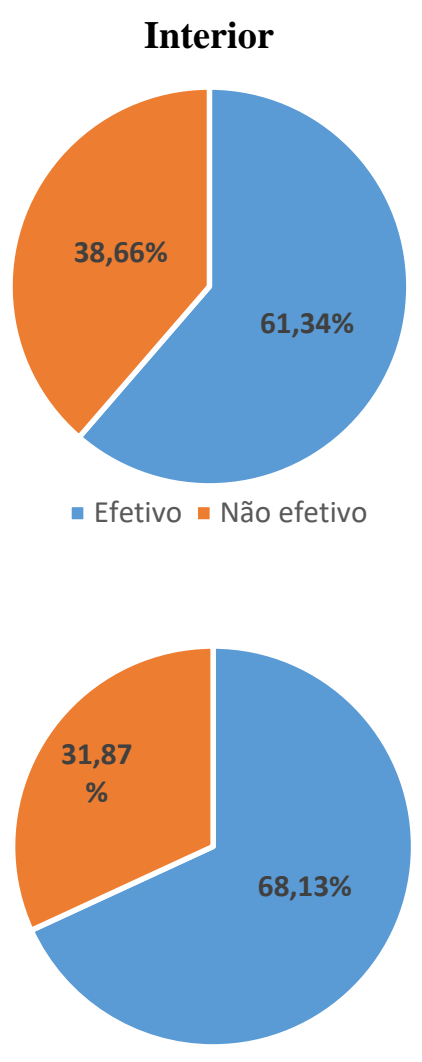

- Efetivo Não efetivo

Gráfico 2 - Distribuição de docentes PEB II (Ensinos Fundamental II e Médio), segundo forma de contratação, por região - 2007 e 2015 (nº abs). Fonte: SEE-SP.

Apreende-se uma sensível redução das formas precárias de trabalho entre 2007 e 2015 entre docentes. Todavia, é importante considerar as diversas transformações que a SEE-SP promoveu em 2015 e 2016, a exemplo do fechamento de salas, aumento do número de alunos por classe e possibilidade de o docente efetivo ministrar disciplinas cuja carga horária no curso de graduação tenha sido de 160 horas. A partir de tal medida encontramos, durante a pesquisa, docentes com carga horária semanal equivalente a 60 horas em sala de aula, o equivalente, em média, a 12 horas diárias em sala de aula, não considerando os períodos de preparação de aulas, correção de atividades, relatórios, preenchimento do diário de classe entre outras atribuições.

Além disso, entre 2015 e 2016 houve variação crescente nas matrículas do ensino médio na ordem de 70.634. Não obstante, 645 classes foram suprimidas. Houve acréscimo de matrículas também na modalidade de Educação de Jovens e Adultos de 16.509 estudantes, mas ampliação de apenas 
19 classes em todo o Estado. A Tabela 3 apresenta esses dados.

Tabela 3 - Variação de matrículas, classes e escolas na rede estadual, ensino presencial, SEE-SP (20152016).

\begin{tabular}{lccc}
\hline Etapas & $\begin{array}{c}\text { Variação de } \\
\text { matrículas }\end{array}$ & $\begin{array}{c}\text { Variação de } \\
\text { classes }\end{array}$ & $\begin{array}{c}\text { Variação de escolas } \\
\text { que oferecem o ciclo }\end{array}$ \\
\hline $\begin{array}{l}\text { Ensino Fundamental } \\
\text { (séries iniciais) }\end{array}$ & -628 & -184 & -23 \\
$\begin{array}{l}\text { Ensino Fundamental } \\
\text { (séries finais) }\end{array}$ & -26.433 & -1956 & -5 \\
Ensino Médio & 70.634 & -645 & 8 \\
Educação de Jovens e Adultos & 16.509 & 19 & -39 \\
Total & 60.082 & -2.766 & -59 \\
\hline
\end{tabular}

Fonte: Cadastro de escolas SEE-SP. Elaboração: Rede Escola Pública e Universidade.

Estudos realizados pela Rede Escola Pública e Universidades ${ }^{5}$ constatam que uma reorganização dissimulada ocorre nas escolas. A despeito de a ação ter sido oficialmente suspensa pela Secretaria de Educação, ela, de fato, vem se materializando de outras formas. O governo do estado impediu que 165 escolas oferecessem, em 2016, turmas de ingresso nos primeiros anos de cada ciclo e 1/3 dessas constava na lista das que seriam fechadas em 2015. Foram extintas 2.404 turmas dos ensinos fundamental e médio no ano de 2016, extinção incompatível com a redução de matrículas que ficou na ordem de 1.336 alunos.

Esses dados associados aos depoimentos dos entrevistados acerca da quantidade de alunos por turma indicam a ocorrência de superlotação de estudantes nas salas de aula, mesmo em escolas que haveria espaço físico para acomodá-los e assim, ser possível reduzir o número de alunos por turma, histórica reivindicação dos professores e movimento sindical, posto que as condições de trabaIho dos docentes teriam significativa melhora. Os dados ${ }^{6}$ permitem analisar também a incidência da precariedade, segundo sexo dos docentes. No segmento dos anos iniciais as mulheres estão presentes maciçamente. Essa curva se diferencia entre os professores licenciados (PEB II), mas, mesmo assim a categoria é predominantemente feminina com participação ligeiramente mais elevada na Grande São Paulo.

\footnotetext{
${ }^{5}$ A Rede foi constituída por iniciativa de professores das universidades públicas do Estado de São Paulo (Unicamp, USP, UFABC, Unifesp) no processo de acompanhamento das ações voltadas à reorganização das escolas, bem como dos movimentos dos estudantes secundaristas que ocuparam os estabelecimentos a serem fechados. Esse grupo foi somado a professores, alunos e pais das escolas estaduais e vem desenvolvendo estudos destinados a observar a reorganização das escolas. 0 estudo ainda não está disponível para consulta.

${ }^{6}$ A série histórica, segundo sexo, é restrita e diferenciada das demais apresentadas neste artigo, pois tal cruzamento é disponibilizado pela SEE-SP apenas a partir de 2007.
} 
A média no período compreendido entre 2007 e 2015 revela que entre os efetivos praticamente 8 em cada 10 professores são do sexo feminino. Se na participação na categoria as mulheres são a maioria, analisando-se os dados referentes aos contratos precários é possível verificar em termos percentuais, que estes incidem em ambos os sexos e em 6 anos, no conjunto de 10, os homens apresentam maior índice de precariedade em relação às mulheres.

Tabela 4 - Distribuição de docentes PEB II, segundo sexo e tipo de contratação.

\begin{tabular}{lcccccc}
\hline Ano & \multicolumn{2}{c}{ Efetivos } & \multicolumn{2}{c}{ Não Efetivos } & \multicolumn{2}{c}{ \% precários } \\
\hline & Fem & Masc & Fem & Masc & Fem & Masc \\
$\mathbf{2 0 0 7}$ & 98228 & 23239 & 68863 & 18584 & 41 & 44 \\
$\mathbf{2 0 0 8}$ & 103.335 & 56.473 & 26.190 & 16.243 & 35 & 22 \\
$\mathbf{2 0 0 9}$ & 98.899 & 25.404 & 62.619 & 17.863 & 20 & 31 \\
$\mathbf{2 0 1 0}$ & 94.291 & 24.306 & 76.161 & 22.500 & 45 & 48 \\
$\mathbf{2 0 1 1}$ & 93.805 & 25.860 & 75.035 & 22.459 & 44 & 46 \\
$\mathbf{2 0 1 2}$ & 93.890 & 27.968 & 74.697 & 23.196 & 44 & 45 \\
$\mathbf{2 0 1 3}$ & 91.944 & 28.053 & 80.597 & 25.942 & 47 & 48 \\
$\mathbf{2 0 1 4}$ & 91.787 & 30.255 & 87.632 & 27.919 & 49 & 48 \\
$\mathbf{2 0 1 5}$ & 98.495 & 35.931 & 63.822 & 17.253 & 39 & 32 \\
$\mathbf{2 0 1 6}$ & 94.647 & 34.522 & 58.747 & 16.904 & 38 & 33 \\
\hline
\end{tabular}

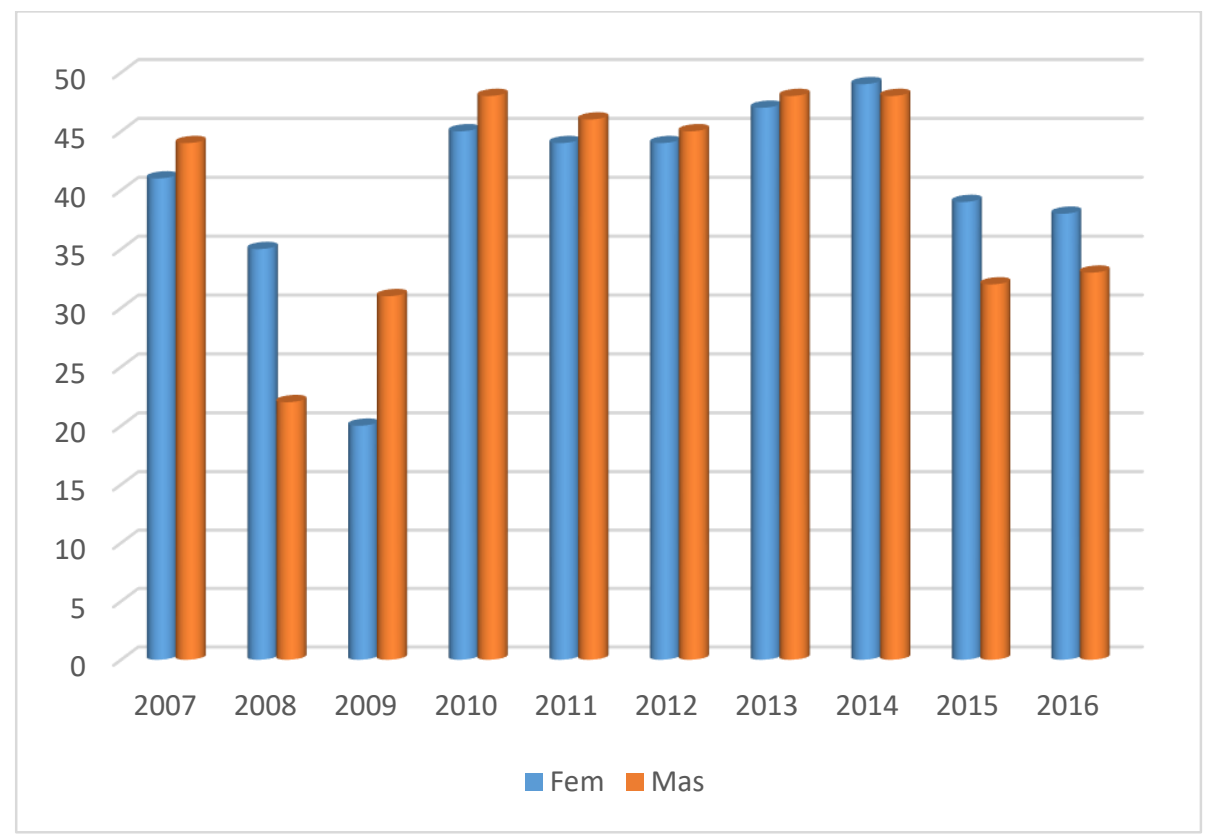

Gráfico 2 - Professores PEB II, segundo sexo e contrato precário - 2007 a 2015 (em \%). Fonte: SEE-SP. Mês de referência: abril. 
Em dez anos de levantamento dos dados, observa-se que a precariedade entre as mulheres é crescente nos últimos três anos, com diferenciações importantes. Movimento semelhante ocorreu com os homens apenas em 2009, quando estes superaram de forma significativa as colegas em termos de contratação temporária.

\section{Trabalho Intelectual Pode Ser Prescrito?}

Os dados concernentes às formas de contratação dos docentes na rede estadual paulista permitem aventar hipóteses que, possivelmente, influenciaram a construção de formas estandardizadas relativas ao ato de ensinar. É possível ilustrar por meio das estatísticas a opção política presente no governo Mario Covas (1ㅇ mandato em 1995 e reeleito em 1998): em 1999, como visto, a quantidade de professores terceirizados superava a dos efetivos. A implementação da Nova Gestão Pública apresentou sinais relativamente céleres de triunfo, pois a redução de custos com a folha de pagamento foi expressiva, mediante a ausência de pagamento de diversos encargos sociais e redução de direitos a essa parcela de trabalhadores se comparada aos funcionários públicos.

Portanto, pondera-se que os professores concursados são, de certa forma, legitimados pelo governado do Estado, pois se submeteram à seleção pública com vistas a avaliar o nível de conhecimento e classificados como aptos ao exercício da docência. Contudo, a parcela de não efetivos é formada por profissionais ou graduandos, que frente à forte ausência de professores nas escolas são chamados, invariavelmente, às vésperas da aula a ser ministrada e que, não necessariamente, seja referente à área de formação. ${ }^{7}$ Encontramos, assim, uma parcela cursando o segundo semestre do ensino superior, alguns realizados a distância e na condição de desempregados se adaptam às condições colocadas pela escola.

Para fazer frente às condições adversas preparam o que chamam "aula coringa". Assim, se a falta do professor for de física, química, inglês etc. ministram a mesma aula:

[...] eu preparei um material diferenciado pra direcionar os alunos dentro da parte de Humanas pro ENEM, então, por exemplo, eu tenho filosofia, sociologia, história, então eu trabalhava com um tema por várias vertentes, fazendo um negócio transdisciplinar, e sempre com a prova do ENEM mesmo, aí fui preparando esses alunos assim, dentro da área de Humanas (professorestudante, 32 anos, não efetivo).

Identifica-se a arquitetura da política voltada ao entrelaçamento de diferentes aspectos, com

\footnotetext{
${ }^{7}$ Sobre isso ver: Jovens professores precários. Disponível em https://vimeo.com/86999810.
} 
vistas a lograr estatísticas favoráveis à educação paulista. Infere-se que a padronização de materiais didáticos atrelados à aferição do aprendizado via prova anual foi construída considerando a precariedade objetiva. Isso porque seus idealizadores reconhecem que metade dos professores não se submeteu à seleção pública e que parte, não mensurada, mas identificada nessa pesquisa, são estudantes universitários e, sobretudo que estes ministram aulas em diferentes disciplinas que não as que estudaram ou ainda estão em curso, um material didático que adote um tom imperativo e prescritivo servirá, de um lado, de apoio à aula improvisada, não preparada e ou ao docente não capacitado para aquela disciplina; e, de outro, formatará o aprendizado com vistas ao teste atrelado à concessão de bônus aos profissionais que atuam nas escolas, concessão eliminada em 2015.

Nessas circunstâncias, os professores são, em grande parte, pressionados a utilizar cada vez mais esse material didático, aqui compreendido como sendo uma tentativa de prescrever o trabalho intelectual praticado pelos docentes, pois considera-se a existência da resistência dos profissionais. Um excerto extraído do livro do professor do referido material oferece margens para compreender a indução na condução da aula:

Antes da leitura: apresente para a sala apenas o título e o nome dos autores e da publicação na qual ele se encontra. Com base nessas informações, questione-os a respeito do que esperam do texto, estimulando a formulação de hipóteses. Com certeza os alunos apresentarão hipóteses muito interessantes (SÃO PAULO, 2009, p. 11).

Os professores identificam os materiais como uma forma de "engessar a criatividade", conforme expressão de alguns entrevistados. Contudo, mobilizam conhecimentos para que a aula ocorra dentro de parâmetros mínimos. Perguntados sobre o uso dos "Cadernos":

[...] eu não sei, a grosso modo eu vejo o caderninho como uma maneira de você engessar a própria questão da criatividade do professor. Por exemplo, o professor quer trabalhar com a questão de ética, aí o livro vai indicar uma série de filmes, mas quando você vai avaliar os filmes, eles adotam a questão ética superficialmente... se você for trabalhar ética, você pode trabalhar com "O Menino do Pijama Listrado", aquele filme ele tem vários debates éticos, você pode pegar o Laranja Mecânica, censura 14 anos, só pro terceiro colegial, filme excelente, mas ele não tá recomendado no caderninho, e quando você vai pegar esse livro, essa questão, de um negócio que ele sai daquele caderno do aluno, ele pode ser mal visto, mal interpretado pelos pais. Por exemplo, o caderninho não debate a questão de gênero, mas como você não vai debater a questão de gênero com toda a discussão que existe no Brasil em torno disso? ... aí se você for falar de gênero, você teoricamente tá falando de gayzice (estudante-professor, 29 anos).

A SEE-SP tem refinado as formas de controle sobre os docentes que desprezam o uso do 
"caderno". Dessa forma, supervisores de ensino, coordenadores pedagógicos e diretores escolares são orientados a participar das aulas dos professores, com vistas a debater, ou de acordo com as entrevistas realizadas, como forma de pressionar seu uso.

\section{Considerações Finais}

O artigo objetivou analisar o trabalho docente à luz de certos aspectos concernentes à política educacional paulista. Constata-se que a implementação da nova gestão pública, iniciada em 1995, vem sendo aperfeiçoada ao longo de mais de vinte anos de governo do mesmo partido político no Estado de São Paulo. Tanto governadores como os responsáveis pela pasta da educação demonstram forte apreço às formas de privatização do ensino público e descaso com a população frente ao depauperamento vivenciado pelas escolas. Em nossas entrevistas pudemos constatar o esforço e o engajamento de diretores, professores e outros profissionais da escola que, sem meios e materiais mínimos capazes de manter as escolas em funcionamento, a exemplo dos materiais de higiene pessoal e limpeza, suprem com seus próprios recursos financeiros os itens de maior urgência. A série histórica construída com dados estatísticos desde 1999 revela que a educação paulista se sustentou, pelo menos nos últimos dezessete anos, com professores não avaliados por concurso público e que atuam em diversas áreas do conhecimento exceto educação física, em razão de legislação específica.

A educação estadual fica, portanto, nas mãos de professores ainda em formação e ou que foram submetidos a uma prova simplificada aplicada nas diretorias regionais, as quais não estabelecem proximidades em relação às executadas nos concursos públicos. Não se desmerece ou invalida, contudo, o trabalho desses profissionais que, buscando uma colocação no mercado, bem como exercer a profissão ou a que está em formação, se submetem a contratos temporários. Mas, ao contrário, visa-se destacar as opções políticas que colocam tanto profissionais quanto a comunidade escolar em situação pouco privilegiada em termos de sobrevivência e de ausência de uma educação integral à população, que prime pela formação de cidadãos.

As discrepâncias verificadas entre a formação, mesmo que ainda em curso, e as disciplinas que os professores temporários devem ministrar, certamente solidificam uma solução para conter os estudantes em sala de aula, mas distante de haver uma preocupação com o conteúdo em desenvolvimento. Do lado dos professores, a situação é igualmente estarrecedora, pois além de improvisarem uma aula são frequentemente desrespeitados pelos estudantes que não os consideram como profissionais. Foram recorrentes, durante as entrevistas, os relatos dos professores não efetivos que declaram situações de humilhação por parte de todos os segmentos presentes na escola: pais, estudantes, 
colegas. Quando, de fato, estão apenas querendo exercer sua atividade profissional.

A opção pela nova gestão pública perseguindo o receituário das empresas vivencia uma contradição que reverbera na formação da Nação. Buscou reduzir custos e terceirizar a força de trabalho; mas, o fez de forma equivocada, pois, como visto, a empresa não terceiriza a essência do negócio, mas o órgão público subcontratou professores, material didático e formação continuada. Indaga-se, assim, quais são as cartas ocultas que ainda faltam ser colocadas à mesa. Um processo de crescente destruição das escolas e da educação pública portaria certa intencionalidade, a exemplo do modelo adotado por FHC que, para privatizar empresas públicas como a telefonia, a energia, mineração entre outras, construiu a imagem de ineficiência do Estado na administração pública e a entregou ao setor privado?

\section{Referências}

AFONSO, A. J. Para uma concetualização alternativa de accountability em educação. Educ. Soc. [online]. v. 33, n. 119, p. 471-484, 2012. Disponível em: <http://www.scielo.br/scielo.php?script=sci_arttext\&pid=S0101-73302012000200008\&lng=pt\&nrm=iso>. Acesso em: 26. jun. 2016.

BALL, S.; YOUDELL, D. Hi discien privatisation in public education. Londres: University of London, 2008. Disponível em: <http://download.ei-ie.org/docs/IRISDocuments/Research\%20Website\%20Documents/2009-00034-01-E.pdf> Acesso em: 16 maio 2015.

BRASIL. Presidência da República. Decreto-lei n 200, de 25 de fevereiro de 1967. Dispõe sôbre a organização da Administração Federal, estabelece diretrizes para a Reforma Administrativa e dá outras providências. Brasília, DOU 1967.

BRASIL. Presidência da República. Decreto $n^{\circ}$ 2.271, de 7 de julho de 1997. Dispõe sobre a contratação de serviços pela Administração Pública Federal direta, autárquica e fundacional e dá outras providências. Brasília, DOU, 1997.

BRESSER PEREIRA, L. Centro Latino Americano de Administração para o Desenvolvimento (CLAD), 1998. Disponível em: <http://www.bresserpereira.org.br/Documents\%5CMARE\%5CCLAD\%5Cngppor.pdf> Acesso em: 10 jun. 2016.

CASTEL, R. Metamorfoses da questão social. Petrópolis: Vozes, 1998.

CORAGGIO, J. L. Propostas do Banco Mundial para a educação: sentido oculto ou problemas de concepção? In: TOMMASI, L. et al. (Orgs.), O Banco Mundial e as políticas educacionais. São Paulo: Cortez, 1996.

HALL, D.; GUNTER, H. M. A nova gestão pública na Inglaterra: a permanente instabilidade da reforma neoliberal. Educ. Soc., Campinas , v. 36, n. 132, p. 743-758, set. 2015. Disponível em: <http://www.scielo.br/scielo.php?script=sci_arttext\&pid=S0101-73302015000300743\&lng=pt\&nrm=iso >. Acesso em: 15 out. 2016.

HARVEY, D. Condição Pós-Moderna. São Paulo: Loyola, 1993 (parte II, p. 115-184).

LINHART, D. Modernisation et précarisation de la vie au travail. Papeles del CEIC, v. 1, p. 1-19, 2009. 
MATTOS, R. A política educacional no estado de São Paulo (2007-2010) e suas articulações com o trabalho docente. 2012. 172 f. Dissertação (Mestrado em Educação) - Programa de Pós-Graduação em Educação. Universidade Metodista de Piracicaba, Piracicaba, 2012.

OLIVEIRA, D. A. A educação básica e profissional no contexto das reformas dos anos 90 . Trabalho \& Educação, Belo Horizonte, n. 8, p. 48-73, jan/jun., 2001.

RIGOLON, W. O que muda, quando tudo muda? Uma análise uma análise do trabalho docente dos professores alfabetizadores do Estado de São Paulo. 2013. Tese (Doutorado em Educação),Universidade Estadual de Campinas, Campinas, 2013.

SÃO PAULO (Estado). Caderno do professor: Ciências. São Paulo: 2009.

SOUZA, A. N. A racionalidade econômica na política educacional em São Paulo. Pro-Posições (Unicamp), Campinas (SP), v. 13, n.1, p. 105-130, 2002.

VENCO, S. RIGOLON, W. Trabalho docente e precariedade: contornos recentes da política educacional paulista. Comunicações. Ano 21, n. 2, p. 41-52, jul.-dez. 2014. Disponível em: <https://www.metodista.br/revistas/revistas-unimep/index.php/comunicacao/article/view/1686/1320>. Acesso em: 22 jun. 2016.

Recebido em outubro de 2016. Aprovado em novembro de 2016. 